\title{
PENGEMBANGAN BUDIDAYA JAMUR TIRAM PUTIH SEBAGAI AGRIBISNIS PROSPEKTIF BAGI GAPOKTAN SEROJA I KANDANG LIMUN BENGKULU
}

\author{
DEVELOPMENT OF OYSTER MUSHROOM CULTIVATION AS \\ PROSPECTIVE AGRIBUSINESS IN GAPOKTAN SEROJA I KANDANG \\ LIMUN BENGKULU
}

\author{
Yenny Sariasih \\ Jurusan Perlindungan Tanaman, Fakultas Pertanian Universitas Bengkulu
}

\begin{abstract}
This activity aims to foster the farmers who are members of Gapoktan Seroja I Kandang Limun, Bengkulu to initiate oyster mushroom cultivationas one of the prospective agribusinesses in Bengkulu. This business was chosen due to the fungus growing medium are available in huge quantities and being waste around Kandang Limun. Further, Oyster mushroom demand and price are high. This event is a program of Ipteks bagi Masyarakat (IBM) in collaboration with the Lembaga Pengabdian Masyarakat (LPM). Training activities include the cultivation, manufacture kumbung measuring 3x4m which capacity of 2000 baglogs, baglog manufacture, sterilization baglog, inoculation, incubation for 3-6 weeks until the harvesting and marketing. Gapoktan Seroja I have been able to make \pm 1500 baglog and have been able to produce white oyster mushroom \pm 5 to10 $\mathrm{kg}$ per day. Fresh mushrooms sold at Rp. 20,000$24.000 / \mathrm{kg}$. With good management and sustainable production, the oyster mushroom cultivation can be one of the prospective agribusiness for Gapoktan Seroja I Kandang Limun, Bengkulu.
\end{abstract}

Keywords: Oyster Mushroom Cultivation, Agribusiness.

\section{PENDAHULUAN}

Gapoktan Seroja I Kelurahan Kandang Limun Bengkulu mulai didirikan pada tahun 2007 dengan anggota sebanyak 77 orang yang berasal dari 5 kelompok tani, yaitu: Kelompok Tani Kesetiakawanan Sosial, Sekundang Serasan, Limun Jaya, Karya Bakti dan Makmur Bersama. Selama ini, Gapoktan ini melakukan beberapa kegiatan usaha yang bersifat musiman, seperti memproduksi pupuk organik, penawaran jasa pembajakan sawah dan 
perontokan gabah pada saat panen disamping bertani dan berkebun. Namun demikian, kegiatan usaha yang telah dilakukan ini dirasakan kurang memberikan kontribusi yang berarti dalam perbaikan perekonomian keluarga para petani dan belum semua anggota terlibat aktif dalam usaha yang masih sangat terbatas tersebut. Oleh sebab itu, para petani yang tergabung dalam Gapoktan Seroja I ini mulai melirik usaha produksi alternatif yaitu produksi jamur tiram putih.

Di Indonesia saat ini, jamur tiram merupakan salah satu komoditas yang mempunyai prospek sangat baik untuk dikembangkan, baik dalam upaya untuk mencukupi permintaan konsumen di dalam negeri yang terus meningkat maupun untuk pasar ekspor, sebab masyarakat sudah mulai mengerti nilai gizi jamur tiram putih (Suhartini dkk., 2007). Selain itu, masyarakat petani ini memilih budidaya jamur tiram putih sebagai produksi pertanian alternatif karena mereka memiliki bahan baku medium perbanyakan jamur tiram putih yang melimpah berupa serbuk gergaji untuk perbanyakan jamur tiram putih. Serbuk gergaji merupakan limbah dari usaha panglong kayu di daerah tersebut dan tidak dimanfaatkan sehingga menjadi tumpukan sampah yang mengotori lingkungan.

Limbah serbuk gergaji ini menjadi bahan baku potensial bagi jamur tiram putih. Dengan ketersediaannya yang melimpah, medium tumbuh jamur tiram putih ini bisa dibuat sebanyak mungkin untuk budidaya jamur tiram putih yang sangat prospektif untuk dikembangkan di kota Bengkulu. Usaha budidaya jamur tiram putih ini dapat memperbaiki tingkat ekonomi petani karena berbasis ekonomi kerakyatan dengan modal yang relatif kecil dan dapat dikerjakan dengan melibatkan seluruh lapisan masyarakat (Meiganati, 2007). Menurut Chazali dan Pratiwi (2009) produksi jamur tiram putih hanya mampu memenuhi $50 \%$ permintaan konsumen dalam negeri, sehingga masih sangat terbuka lebar kesempatan untuk mengembangkan agribisnis ini. Situasi ini merupakan prospek yang baik untuk usaha produksi jamur tiram putih. Dengan pembinaan dan pendampingan yang baik maka produksi jamur tiram putih ini dapat menjadi agribisnis yang prospektif untuk dikembangkan oleh Gapoktan Seroja I. Kegiatan ini merupakan program Iptek bagi Masyarakat (IbM) berbasis kebutuhan Mitra Gapoktan Seroja I dan bertujuan untuk membina para petani yang tergabung dalam Gapoktan Seroja I untuk merintis usaha budidaya jamur tiram putih sebagai salah satu pengembangan agribisnis yang prospektif di Kota Bengkulu dan membuat analisis usaha sederhana dari usaha budidaya jamur tiram putih. 


\section{METODE PENELITIAN}

Dalam merintis usaha budidaya jamur tiram putih ini, Gapotan Seroja I mendapat pelatihan dan pendampingan dari Tim Dosen Universitas Bengkulu melalui program Iptek bagi Masyarakat (IbM) Dikti bekerja sama dengan Lembaga Pengabdian Masyarakat Universitas Bengkulu (LPM UNIB). Program dilakukan selama 6 bulan dengan melibatkan pengurus dan anggota Gapoktan Seroja I.

Bahan yang digunakan dalam kegiatan ini adalah bibit jamur tiram putih, plastik tahan panas PP, Kapas, serbuk gergaji, dedak, kapur, dan cincin jamur. Sedangkan peralatan yang digunakan adalah drum untuk sterilisasi, cangkul, sekop, lampu spiritus dan peralatan lain yang relevan digunakan untuk kegiatan budidaya jamur tiram putih.

Kegiatan diawali dengan pelatihan budidaya jamur tiram putih selama satu hari penuh dan kemudian keesokan harinya dilanjutkan dengan praktek pembuatan medium tumbuh jamur tiram, sterilisasi, inokulasi bibit hingga inkubasi baglog pada kumbung yang telah disiapkan. Kumbung yang dibangun berukuran $3 \times 4 \mathrm{~m}$ yang berdaya tampung sekitar 2000 baglog. Kumbung dibangun dengan bahan utama anyaman bambu, atap rumbia dan rak-rak baglog terbuat dari bambu. Kumbung dilengkapi dengan thermometer untuk mengukur suhu di dalam kumbung. Kumbung menjadi tempat baglog diinkubasikan setelah baglog diinokulasi dengan bibit jamur tiram putih.

Baglog dibuat dengan mencampur serbuk gergaji, bekatul 15\% dan kapur pertanian 3\% dan air 60\% dari jumlah serbuk gergaji yang akan digunakan. Campuran bahan ini dimasukkan ke dalam kantong plastik tahan panas PP, ditutup dengan cincin jamur, disumbat dengan kapas dan ditutup kembali dengan kertas dan diikat karet. Setelah baglog selesai dibuat, baglog disterilisasi dengan dikukus di dalam drum selama 4-6 jam. Kemudian baglog dibiarkan hingga dingin, dan setelah dingin baglog diinokulasi dengan bibit jamur tiram putih serta diinkubasikan ke dalam kumbung. Masa inkubasi hingga siap panen dibutuhkan waktu sekitar 3 hingga 6 minggu.

\section{HASIL DAN PEMBAHASAN}

Salah satu komoditi pertanian yang pada saat ini mengalami ketidakseimbangan antara permintaan dan penawarannya adalah jamur tiram putih, karena tingginya permintaan konsumen akan jamur tiram segar di pasar tidak diiringi oleh peningkatan produksi jamur tiram putih di dalam negeri (Rahmawati, 2012). Kondisi ini memberikan peluang bagi para petani jamur tiram putih khususnya Gapoktan Seroja I untuk merintis usaha budidaya jamur tiram putih sebagai salah satu pengembangan usaha kelompok tani. 
Usaha budidaya jamur tiram putih bagi Gapoktan Seroja I dimulai dengan pembangunan kumbung jamur tiram putih berukuran $4 \times 3 \mathrm{~m}$ yang berdaya tampung sekitar 2000 baglog jamur (Gambar 1a). Tahap selanjutnya adalah pembuatan baglog (Gambar 1b dan 1c), sterilisasi baglog (Gambar 1d), inokulasi bibit (Gambar 1e) hingga inkubasi baglog (Gambar 1f), dilakukan oleh seluruh anggota dan pengurus Gapoktan Seroja I secara bergotongroyong.

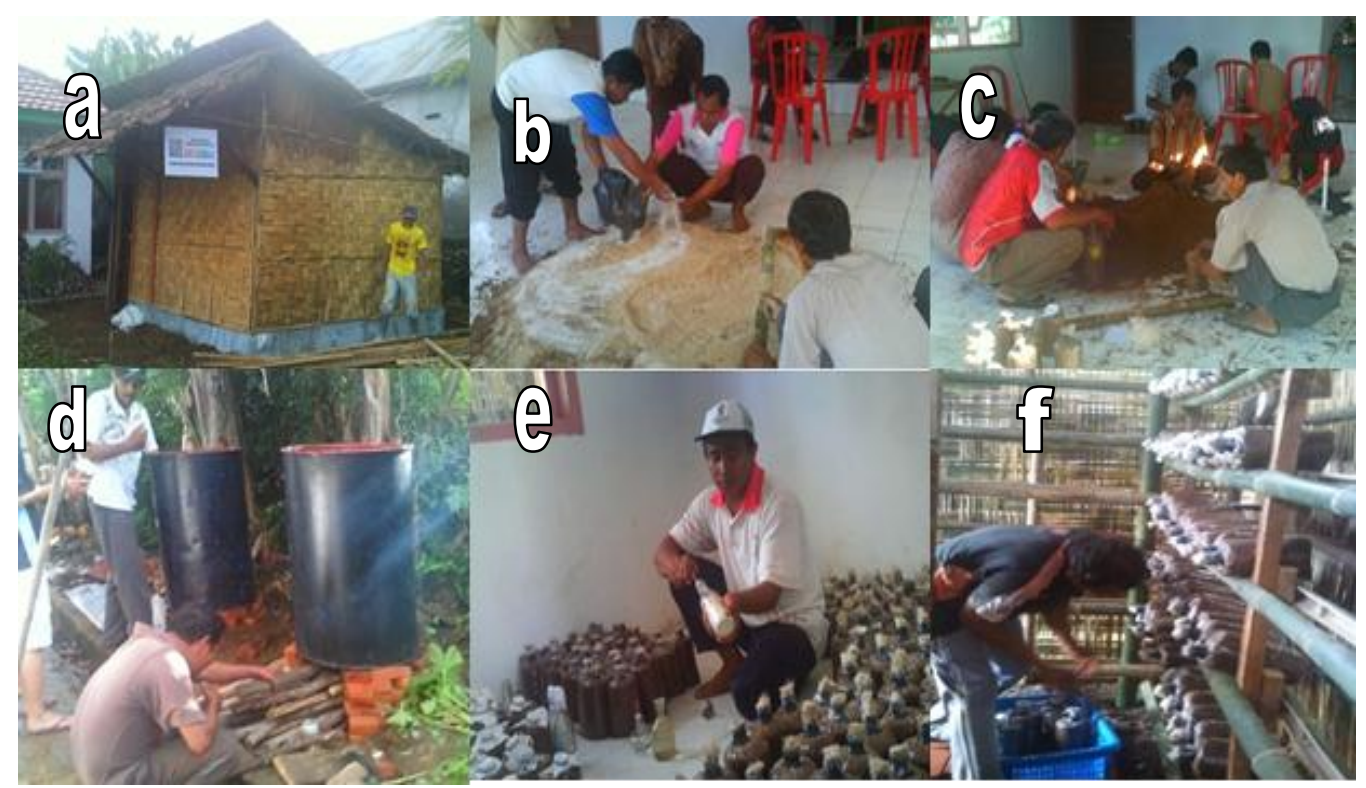

Gambar 1.

a. Kumbung Jamur Milik Gapoktan Seroja I, b dan c. Pembuatan Baglog, d. Sterilisasi dengan Drum, e. Inokulasi Bibit, f. Inkubasi Baglog dalam Kumbung

Pembuatan baglog dilakukan secara periodik per dua minggu agar baglog yang siap dipanen tersedia setiap hari. Semakin banyak baglog yang dibuat, maka semakin banyak jamur tiram putih yang siap dipanen dan dipasarkan. Baglog diinkubasikan selama 3 hingga 6 minggu hingga miselium jamur tumbuh di seluruh permukaan baglog dan kemudian tubuh buah jamur tiram putih akan keluar dari lubang yang telah dibuat di atas atau samping dari baglog.Untuk memaksimalkan pertumbuhan tubuh buah jamur tiram putih maka harus memperhatikan syarat tumbuh optimal dari jamur tiram putih. Menurut Suriawiria (2002) syarat tumbuh jamur tiram putih meliputi temperature, kelembaban, kandungan $\mathrm{CO} 2$ dan cahaya. Sehingga syarat tumbuh ini harus menjadi perhatian petani budidaya jamur tiram putih agar hasil panen dapat optimal. Jamur Tiram putih siap dipanen apabila tubuh 
jamur telah mekar sempurna dan harus segera dipanen sebelum berwarna kuning dan layu. Panen sebaiknya dilakukan di pagi hari. Jamur tiram putih produksi Gapoktan Seroja I disajikan pada Gambar 2.

Selain pelatihan budidaya jamur tiram putih, petani diberi pelatihan penanganan pasca panen yang baik agar produk jamur tiram putih tetap segar ketika dipasarkan. Jamur tiram putih sebaiknya dipanen di subuh hari pukul 5 sampai 6 pagi. Jamur tiram putih yang siap panen adalah yang tubuh buahnya cukup besar tapi belum pecah tepinya, biasanya setelah 3 hari sejak kemunculan yang pertama keluar dari baglog. Jamur tiram putih yang telah dipanen langsung dimasukkan dalam plastik dan ditimbang 0,5 - $1 \mathrm{~kg}$ per kantong dan disegel atau dipress bagian atasnya agar kedap udara sehingga kelembapannya tetap terjaga (Gambar 2c). Kemudian jamur yang telah dipress ini langsung dimasukkan ke dalam lemari pendingin agar kondisi tubuh buah tetap segar hingga dipasarkan ke konsumen dan penampilan produk lebih menarik. Plastik kemasan juga diberi label usaha Gapoktan Seroja I dengan disertai alamat dan nomor kontak agar konsumen di luar daerah dapat memesan jamur tiram putih lewat telepon atau langsung mendatangi alamat tempat usaha. Dengan demikian usaha jamur tiram putih ini dapat berkelanjutan.

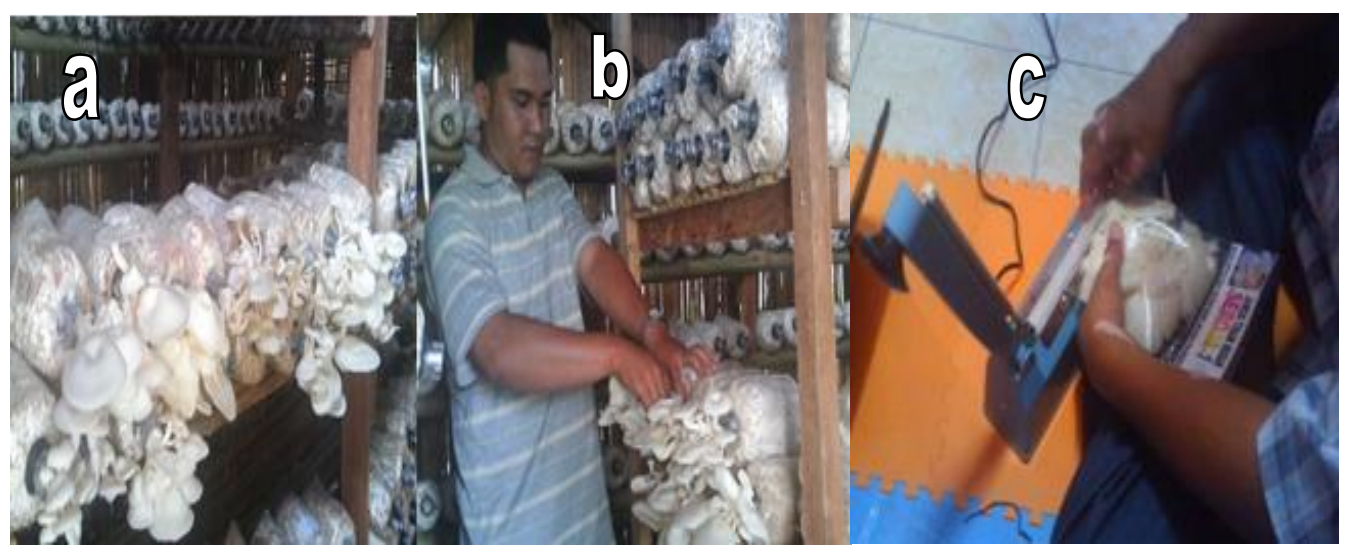

Gambar 2.

Jamur Tiram Putih yang siap dipanen dan dikemas

Setiap baglog mampu menghasikan 0,3-0,8 kg jamur tiram putih, jadi 10 baglog bisa menghasilkan 3-8 kg jamur tiram putih segar. Satu kg jamur tiram putih di Bengkulu dijual dengan harga Rp.20.000-24.000,-, maka apabila dalam satu hari mampu menjual $8 \mathrm{~kg}$ jamur tiram putih, akan memperoleh Rp.160.000-Rp.192.000 per hari. Analisis usaha budidaya jamur tiram putih adalah sebagai berikut: 
ISSN: 1412-8837

\section{Analisis Usaha Budidaya Jamur Tiram Putih}

Biaya Produksi 1000 baglog jamur:

a. Bahan Baglog

Serbuk kayu 1000 kg@ Rp. 1000

$=$ Rp. 1.000.000,-

Bekatul 150 kg @ Rp. 4500

$=$ Rp. 675.000,-

Kapur 30 kg@ Rp. 4000

$=$ Rp. 120.000,-

Bibit 50 botol @ Rp. 10.000

$=$ Rp. $500.000,-$

Total biaya 1

Rp. 2.295.000,-

b. Perlengkapan

Kumbung 1 unit

Drum 2 unit @ Rp. 200.000

Plastik Tahan Panas (PP) 10 kg @ Rp.20.000

Cincin Jamur 1000bh @Rp. 100

Kapas Penyumbat cicin jamur $2 \mathrm{~kg}$

Upah Tenaga Penyiram 1 orang

Total biaya 2
$=$ Rp. 4.000.000,-

$=$ Rp. $400.000,-$

$=$ Rp. 200.000,-

$=$ Rp. 100.000,-

$=$ Rp. $\quad 90.000,-$

$=$ Rp. $\quad 500.000,-$

Rp. 5.290.000,-

Total 1 dan 2 = Rp. $2 \cdot 295.000+5.290 .000,-$ $=$ Rp. 7.585.000,-

Pendapatan:

a. 1000 baglog menghasikan 300kg sekali panen, $300 \mathrm{~kg} @ \mathrm{Rp} \cdot 20.000=$ Rp.6.000.000,-/panen

b. 1 baglog 3-5 kali panen, misal 3 kali panen $=$ Rp. $6.000 .000 \times 3=$ Rp.18.000.000,-

c. Keuntungan dalam sekali produksi $=$ Rp. 18.000.000-Rp.7.585.000,- $=$ Rp.10.415.000,-

Dengan perhitungan analisis usaha di atas, maka usaha budidaya jamur tiram putih ini cukup prospektif untuk dikembangkan menjadi agribisnis bagi Gapoktan Seroja I. Dari analisis usaha diketahui bahwa dalam sekali produksi atau sekitar \pm 3 hingga 5 bulan usaha budidaya jamur tiram putih dapat melewati Break Event Point (BEP). Analisis usaha yang disajikan merupakan perhitungan apabila produk jamur tiram putih dijual secara segar, padahal jamur tiram putih dapat diolah dan dijual dalam bentuk produk olahan seperti kripik dan abon jamur yang tentu akan lebih menjanjikan secara ekonomi lebih

16 | Yenny Sariasih, Pengembangan Budidaya Jamur Tiram Putih.... 
besar. Usaha jamur tiram putih semakin menjanjikan karena melihat minat masyarakat untuk mengkonsumsi jamur tiram putih terus meningkat sehingga berpengaruh positif terhadap permintaan jamur tiram putih (Zulfahmi, 2012). Bila agribisnis ini dapat diteruskan secara berkelanjutan, maka hasil usaha ini dapat berdampak langsung bagi pendapatan Gapoktan Seroja I. Hasil pendapatan ini dapat dinikmati oleh para petani yang tergabung dalam Gapoktan Seroja I dan diharapkan kesejahteraan petani yang tergabung dalam Gapoktan Seroja I dapat meningkat.

\section{KESIMPULAN}

Berdasarkan hasil dan pembahasan dapat disimpulkan bahwa usaha budidaya jamur tiram putih dapat menjadi agribisnis yang prospektif bagi Gapoktan Seroja I Kandang Limun dalam upaya merintis agribisnis unggulan di Provinsi Bengkulu. Produksi jamur tiram segar dari 1000 baglog telah mampu menembus BEP sehingga sangat menjanjikan. Dengan manajemen budidaya yang baik, maka agribisnis budidaya jamur tiram putih dapat meningkatkan pendapatan organisasi Gapoktan Seroja I dan meningkatkan kesejahteraan petani yang tergabung di dalamnya di masa yang akan datang.

\section{DAFTAR PUSTAKA}

Chazali, S., dan P.S. Pratiwi. 2009. Usaha Jamur Tiram Skala Rumah Tangga. Penebar Swadaya. Depok.

Meiganati, K.B. 2007. Analisis Finansial dan Kelembagaan Usaha Jamur Tiram Putih untuk Pemanfaatan Limbah Industri Penggergajian. http://repository.ipb.ac.id/handle/ 123456789 9490. Diakses 5 Maret 2013.

Rahmawati, J. 2012. Analisis Kelayakan Pengembangan Usaha Budidaya Jamur Tiram Putih (Kasus: Usaha Jamur Mandiri, Kabupaten Bogor). http://repository.ipb.ac.id/handle/123456789/56175. Diakses 10 Maret 2013.

Suhartini, T. Aminatun, V. Henuhili. 2007. Pelatihan Budidaya Jamur Tiram Dengan Sistem Susun Pada Masyarakat Desa Kasihan, Bantul Sebagai Upaya Meningkatkan Pendapatan Keluarga http://staff.uny.ac.id/sites/ default/files/pengabdian/ir-suhartini-ms/artikel-jamur-tiram-07.pdf. Diakses 10 Maret 2013.

Suriawiria, U. 2002. Budidaya Jamur Tiram. Kanisius. Yogyakarta. 
ISSN: $1412-8837$

Zulfahmi, M. 2012. Analisis biaya dan pendapatan usaha jamur tiram putih model pusat pelatihan pertanian perdesaan swadaya (p4s) Nusa Indah. Fakultas Sains Dan Teknologi Uin Syarif Hidayatullah Jakarta. http://repository.uinjkt.ac.id/dspace/handle/123456789/1672.

Diakses 10 Maret 2013.

18 | Yenny Sariasih, Pengembangan Budidaya Jamur Tiram Putih.... 